\title{
On the use of the P300 as a tool for cognitive processing assessment in healthy aging A review
}

Sofia Cristina lost Pavarini ${ }^{1,2,4}$, Allan Gustavo Brigola1, Bruna Moretti Luchesi ${ }^{1}$, Érica Nestor Souza1, Estefani Serafim Rossetti ${ }^{1}$, Francisco José Fraga ${ }^{3}$, Letícia Pimenta Costa Guarisco ${ }^{4}$, Marélli Terassi ${ }^{1}$, Nathalia Alves Oliveira ${ }^{1}$, Priscilla Hortense ${ }^{1}$, Renata Valle Pedroso ${ }^{5}$, Ana Carolina Ottaviani ${ }^{1}$

ABSTRACT. Changes in patterns of performance for the cognitive functions of memory, processing speed, and focused attention are expected in old age. Objective: The main goal of this systematic review was to analyze the use of ERP in healthy elderly in studies evaluating the P300 components. Methods: A systematic review was carried out based on recommendations for nursing research on the databases LILACS, PsycINFO, PubMed, SCOPUS and Web of Science. Results: 26 studies involving 940 healthy elderly were identified, most of which sought to identify and determine the influence of age on the P300. Conclusion: Although there is consensus in the literature that P300 latency is significantly longer in elderly with psychiatric disorders compared to healthy elderly, it was not possible to conclude P300 associations with gender, education and other cognitive tests.

Key words: aging, neuropsychological function, event-related potentials, P300, healthy elderly.

O USO dO P300 COMO FERRAMENTA PARA AVALIAÇÃO dO PROCESSAMENTO COGNITIVO EM ENVELHECIMENTO SAUDÁVEL RESUMO. São esperadas mudanças nos padrões de desempenho nas funções cognitivas de memória, velocidade de processamento e atenção concentrada durante o processo de envelhecimento. Objetivo: 0 objetivo principal desta revisão sistemática é analisar o uso de ERP em idosos saudáveis nos estudos que avaliaram os componentes do P300. Métodos: Realizou-se uma revisão sistemática com recomendações de estudo para enfermagem nos bancos de dados LILACS, PsycINFO, PubMed, SCOPUS and Web of Science. Resultados: Foram identificados 26 estudos com 940 idosos saudáveis, a maioria procurava identificar e encontrar a influência da idade no P300. Conclusão: Embora haja consenso na literatura de que em idosos com transtornos psiquiátricos a latência P300 é significativamente maior, em relação aos idosos saudáveis não foi possível concluir as associações P300 com gênero, escolaridade e outros testes cognitivos. Palavras-chave: envelhecimento, função neuropsicológica, potencial relacionado a eventos, P300, idosos saudáveis.

Some age-related changes in brain funcStion are expected. Therefore, changes in attention, concentration and memory may influence cognitive processing ${ }^{1}$ and because they are associated with these functions, endogenous event-related potentials (ERP) have been used to supplement neuropsychological evaluation. Endogenous ERP do not depend only on the individual's physi- cal attributes, but also on brain reactions. ${ }^{2}$ The ERP are magnetic waves (measured by magnetoencephalography - MEG), where the third positive wave is known as $\mathrm{P} 3$ or P300, since it occurs around 300 milliseconds (ms) after the presentation of the stimulus. Two variables are used to quantify the P300: latency, which is related to information processing time, and amplitude, which is related

This study was conducted at Federal University of São Carlos (UFSCar), SP, Brazil.

${ }^{1}$ PhD, Federal University of São Carlos (UFSCar), Graduate Program in Nursing, São Carlos, SP, Brazil. ${ }^{1} M S$, Federal University of São Carlos (UFSCar), Graduate Program in Nursing, São Carlos, SP, Brazil. ${ }^{2} \mathrm{PhD}$, Federal University of São Carlos (UFSCar), Graduate Program in Gerontology, São Carlos, SP, Brazil. ${ }^{3} \mathrm{PhD}$, Federal University of ABC (UFABC), Engineering, Modeling and Applied Social Sciences Center (CECS), Santo André, SP, Brazil. "PhD, Federal University of São Carlos (UFSCar), Gerontology Department, São Carlos, SP, Brazil. 5PhD, São Paulo State University (UNESP), Physical Activity and Aging Lab, Rio Claro, SP, Brazil.

Sofia Cristina lost Pavarini. Graduate Program in Gerontology / Federal University of São Carlos (UFSCar) - Rodovia Washington Luís Km 310 - $13565-905$ São Carlos SP - Brazil. E-mail: sofia@ufscar.br

Disclosure: The authors report no conflicts of interest.

Received August 23, 2017. Accepted in final form October 26, 2017.

(c) BY 
to attention level. ${ }^{3}$ To evaluate the classic P300 (P3b), the oddball paradigm is usually used, by which subjects are instructed to discriminate the rare stimulus while irrelevant stimuli are also being presented. Tasks can be auditory, with stimuli at different sound frequencies, for instance, or visual, entailing presentation of figures. ${ }^{4,5}$

The variation in cognitive processing in the elderly, according to the literature, ranges from $300 \mathrm{~ms}$ to 400 $\mathrm{ms}$ or longer. There is evidence that a reduction in cognitive processing speed occurs with aging, characterized by increased latency and decreased amplitude. ${ }^{2,5-9}$

The literature indicates that cognitive processing can be influenced by factors such as age, gender, education, reading habits, cognitive performance, the presence of depressive symptoms, level of social and cultural interaction, among other aspects. ${ }^{10,11} \mathrm{~A}$ meta-analysis study found that P300 is a sensitive tool for monitoring cognition and may be an indicator in the analysis of cognitive deterioration. ${ }^{4}$

Given the above, the need to know and systematize the data on the use of the P300 for cognitive processing assessment in healthy elderly was recognized, considering that reviews published to date have focused on the association between age and cognitive processing in elderly with cognitive impairment.

The main goal of this systematic review was to analyze the use of ERP in healthy elderly in studies evaluating the P300 components, primarily the classical P300, with a focus on attention and cognitive processing speed. The intention was to identify the most relevant and recent output on the subject and provide information that can help guide the use of the P300 in elderly as a tool for cognitive processing assessment, both for clinical practice and research. Besides the above-mentioned objective, this study also aimed to identify evidence of the relationship between P300 and associated factors (age, gender, and education) in healthy aging.

\section{METHODS}

This was a systematic review of the literature, carried out according to the stages recommended in the literature. ${ }^{12}$ The guiding questions that underpinned this review were "What are the characteristics about the recent output using the $\mathrm{P} 300$ for cognitive processing assessment in healthy elderly?" and "Can individual associated factors such as age, gender and education influence P300 in healthy elderly? What is the scientific evidence?".

The inclusion criteria were studies that used the P300 as a tool for evaluating cognitive processing in the elderly and that included at least one group of cog- nitively healthy elderly in the sample; studies with a publication date of between January 2011 and January 2017; and articles written in Portuguese, English or Spanish. Although the P300 has been studied over the last 50 years, in this study the analysis was focused on the recent and relevant output regarding its use as a tool for cognitive processing speed and attention assessment, since numerous good reviews have been published on early P300 studies in general.

The exclusion criteria were articles that used types of event-related potentials other than the classic P300, studies that did not include a cognitively healthy elderly group and those not having a focus on cognitive processing speed and attention.

\section{Search strategy}

We selected studies through electronic searches on five health databases: LILACS; PsychINFO; PubMed; SCOPUS and Web of Science, using the following combination of descriptors and filters: ("P300" OR "electrophy siological" $O R$ "evoked cognitive potentials" $O R$ "evoked potential" OR "auditory evoked potentials") AND "elderly"; Activated filters: Research in humans, Aged: $65+$ years, 80 and over: $80+$ years.

\section{Study selection}

Two independent "blind" reviewers conducted the search for titles and abstracts in July 2016. The studies that addressed the guiding questions were selected for full reading using a selection protocol previously created in Microsoft Excel ${ }^{\circledR} 2010$. In addition, a strategy of cross-reference searching was performed, by which all the references from the selected studies that addressed the guiding questions and met the inclusion criteria were selected for full reading. Reading and discussion of the studies were carried out intensively in a consensus meeting held on February 05, 2017 with the presence of authors.

Figure 1 depicts a summary of the steps for the study identification and selection procedure with numerical data.

\section{Data collection, analysis and synthesis of results}

For the analysis and extraction of the data from the articles retrieved, a form devised by the authors collecting the following information was used: authors; publication year; country; study design; aims; sociodemographic information on the sample; auditory or visual ERP; complementary evaluation; statistical tests used; and main findings. The information was gathered in spreadsheets. The quantitative data were presented as 
simple frequency, percentage and mean. The qualitative analyses of the studies were carried out together with all the authors and presented in text and tables.

As a secondary and complementary result, the studies that reported amplitude and latency information for the healthy elderly were described and summarized in the review.

\section{RESULTS}

\section{General characteristics of the studies}

Of the 26 articles selected, 22 were cross-sectional studies and four randomized clinical trials. Regarding the publication date, most were published in 2014 (30.8\%) and 2013 (30.8\%). The studies were conducted in 12 different countries, $26.9 \%$ in the United States, and $11.6 \%$ in Japan, Italy, Brazil, Canada, and China.

Concerning the sample characteristics, the studies included information from 1,463 participants, of which 940 were healthy elderly. Regarding participant age, 23 studies cited the mean age of the healthy elderly groups, where the lowest average found was 60.0 years $^{13}$ and

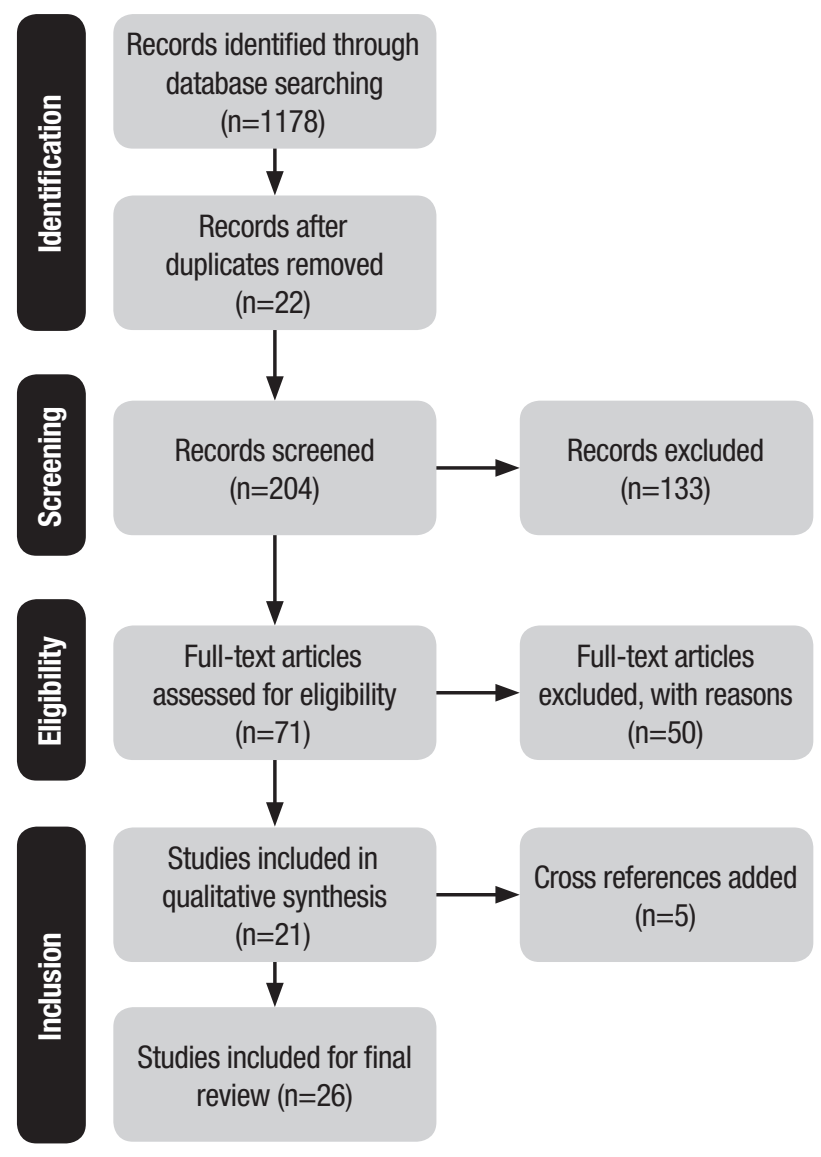

Figure 1. Summary of the study search and selection procedure. São Carlos, 2017. the highest was 75.8 years. ${ }^{14}$ The majority $(n=10)$ had a mean age of between 70 and 74 years. ${ }^{2,15-20}$ Two studies did not cite the mean age, only the age range of the participants, which was $15-85$ years ${ }^{21}$ for one study and 42-78 years for the other. ${ }^{22}$

With regard to the type of stimulus used for obtaining the P300, 50\% used auditory stimulation and 50\% visual stimulation, and each study used different settings for recording the ERP. Most studies (92.3\%) used complementary evaluations and $23 \%$ also included electrophysiological evaluation of waves other than the P300.

\section{P300 evaluation}

The evaluation of $\mathrm{P} 300$ was used in $53.8 \%$ of the articles to identify the influence of age on cognitive processing performance. ${ }^{5,15-17,19,21,23-29}$ In $19.2 \%$ of the studies, the P300 was used to compare the electrophysiological evaluation of healthy and cognitively impaired participants, ${ }^{6,13,14,30,31} 15.4 \%$ used electrophysiological evaluation to monitor the effects of therapies in clinical trials, ${ }^{32-35}$ one study evaluated the P300 according to age, depression, and cognition, ${ }^{2}$ one evaluated depression in post-stroke patients ${ }^{22}$ and one paper studied the difference between older monolingual and bilingual adults. ${ }^{18} \mathrm{~A}$ summary of the results is given in Table 1.

\section{P300 values}

Of the 26 studies, eight reported means and standard deviations of the P300 values (amplitude and latency), as summarized in Table 2 . These values are only for the healthy elderly groups, serving as a reference for discussion of the subsequent studies.

The statistical procedures most used for the treatment of P300 data were those recommended when the data adhere to normality. The variance analysis by ANOVA was the most used (61.5\%), the $t$-test was the most used procedure for comparison of groups and therapy effects (28\%), and the non-parametric option predominantly used to compare the ranking between groups was the Mann-Whitney test. The Spearman (16\%) and Pearson (8\%) correlation coefficients were used for correlation analyses.

Regarding the most evident findings, half of the articles found an influence of age on P300 values. In $19.2 \%$ of the studies, associations between neurocognitive impairment and worse electrophysiological evaluation ${ }^{6,13,14,30,31}$ were found. Education was an item commonly not associated with P300 evaluation. ${ }^{2,16,27}$ Two articles presented contrasting results for the association between sex and P300 values - the first study found that 


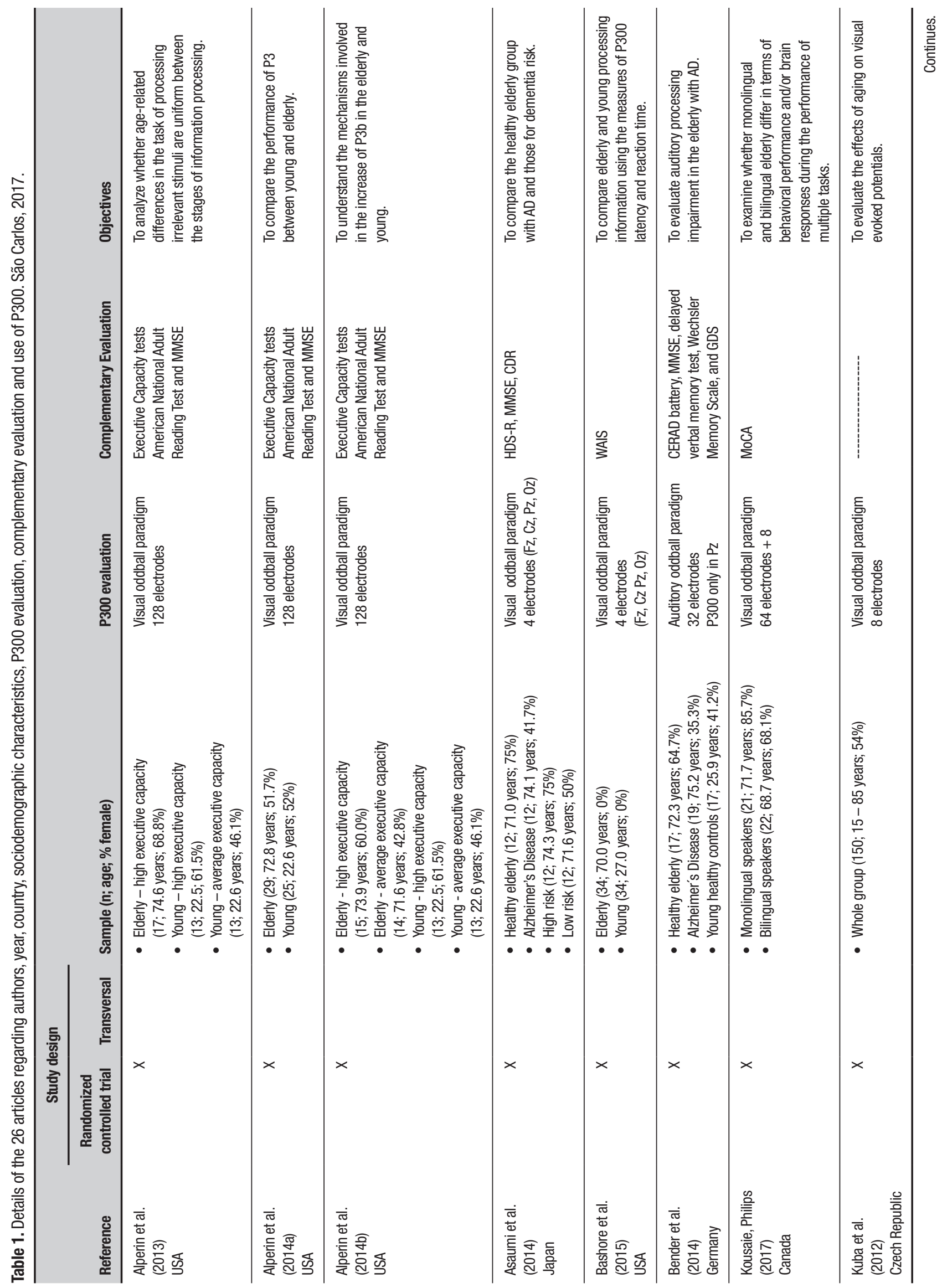




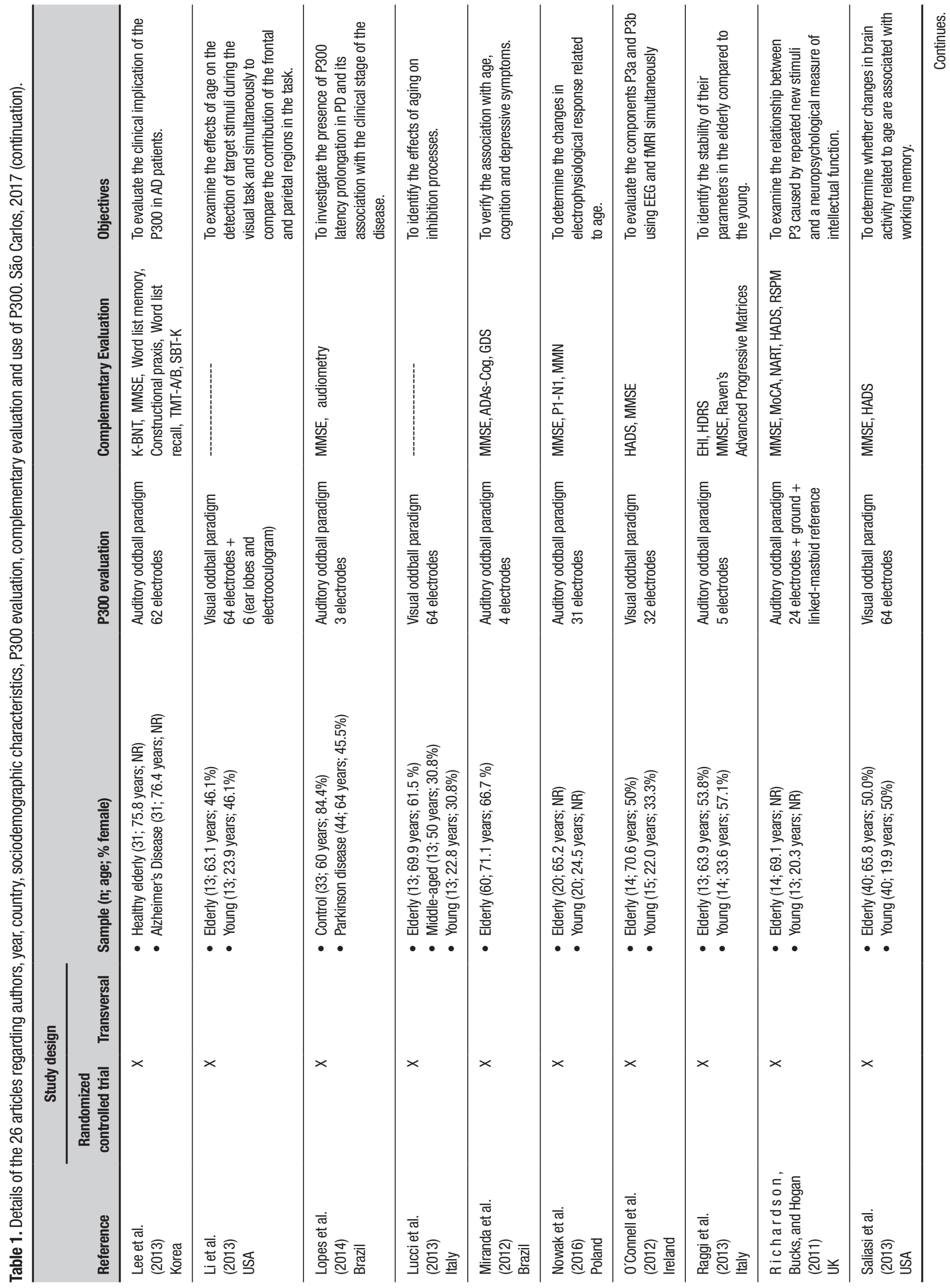




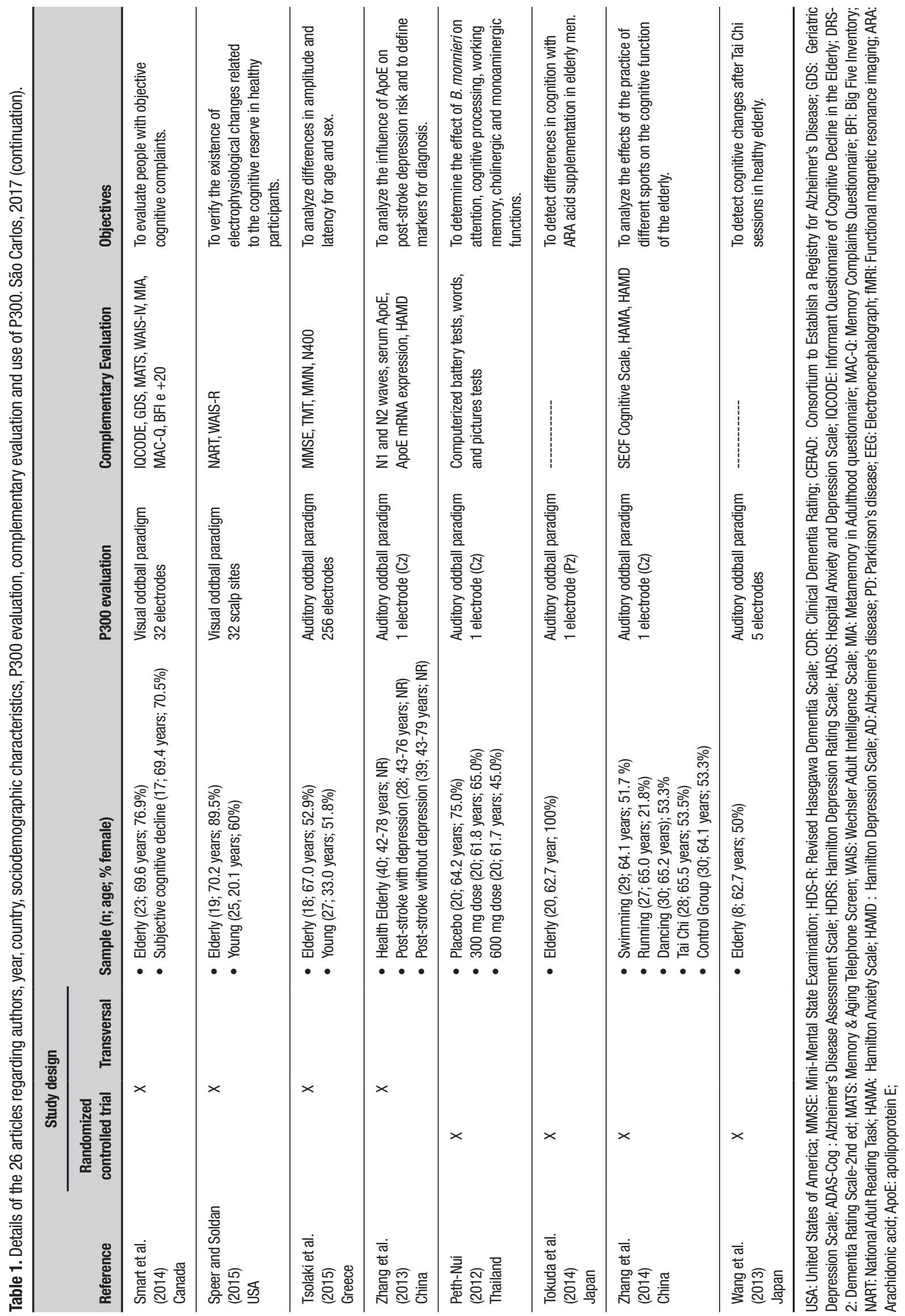


latency in the male group was greater with advancing years ${ }^{21}$ whereas the second found that response to the stimulus in the frontal region was faster in men. ${ }^{5}$ Four studies performed an association analysis between neuropsychological and cognitive tests with P300 values, although two of these failed to identify a relationship between the two variables. In both studies that demonstrated this association, the authors confirmed a relationship between P300 and the working memory domain in healthy elderly ${ }^{29}$ and for general scores on word list recognition, constructional praxis, and word fluency neuropsychological tests of the MMSE and CERAD-K in elderly with Alzheimer's disease. ${ }^{14}$ Finally, one study examined the difference between monolingual and bilingual elderly in terms of brain response during the performance of multiple tasks. ${ }^{18}$

The amplitude and latency values of P300 in healthy elderly are given in Table 2, showing no pattern of response to the stimuli among the studies described. The amplitude values ranged from $2.2 \mu \mathrm{V}( \pm 0.2)^{31}$ to 18.5 $\mu \mathrm{V}( \pm 9.2)^{34}$ and latency values from $320 \mathrm{~ms}( \pm 20.2)^{22}$ to $484 \mathrm{~ms}( \pm 21),{ }^{31}$ independently of the channel (electrode) used to capture the response to the stimulus.

\section{DISCUSSION}

\section{P300: sociodemographics and values in healthy elderly}

Of the cross-sectional studies that included a control group, 14 evaluated the effects of healthy aging on endogenous evoked potentials., ${ }^{5,15-17,19-21,23-29}$ In all studies, age influenced cognitive processing. These data corroborate a review study that indicated a decrease in P300 amplitude at advanced ages. ${ }^{9}$ Another integrative review reported that latency tends to increase, and amplitude to decrease, with advancing age. ${ }^{36}$

On average, the P300 latency increases by around $2 \mathrm{~ms}$ per year, as wave amplitude is linearly reduced in older people. ${ }^{21}$ The data found corroborates the findings of a study that estimated the latency effect of P300 in 62 healthy elderly subjects and subdivided them into three groups according to age: 60-64 years, 65-69 years and 70-74 years. The researchers found a linear significant increase of $2.85 \mathrm{~ms}$ per year in the age groups $65-69$ years and $70-74$ years. $^{8}$

The articles also showed that the P300 amplitude values ranged from $2.2 \mu \mathrm{V}$ to $18.5 \mu \mathrm{V}$ and the latency values from $320 \mathrm{~ms}$ to $484 \mathrm{~ms}$. These variations found may be related to the characteristics of the samples studied, the variables analyzed and the methods adopted in each study.

The increase in wave amplitude may result in increased use of frontal executive functions as a com-
Table 2. P300 values in healthy elderly. São Carlos, 2017.

\begin{tabular}{|c|c|c|}
\hline \multirow[b]{2}{*}{ Study } & \multicolumn{2}{|c|}{ Mean \pm standard deviation } \\
\hline & Amplitude $(\mu \mathrm{V})$ & Latency (ms) \\
\hline \multirow[t]{3}{*}{ Lee et al. (2013) } & $6.5 \pm 5.5^{\star}$ & $362.5 \pm 44.2^{*}$ \\
\hline & $4.0 \pm 2.8^{\star \star}$ & $362.2 \pm 43.5^{\star \star}$ \\
\hline & $4.1 \pm 5.5^{\star \star \star}$ & $385.1 \pm 38.5^{\star \star \star}$ \\
\hline \multirow[t]{3}{*}{ Raggi et al. (2013) ${ }^{\mathrm{a}}$} & $5.3 \pm 2.6^{*}$ & $357.8 \pm 30.9^{\star}$ \\
\hline & $6.6 \pm 2.7^{\star \star}$ & $357.2 \pm 31.3^{\star \star}$ \\
\hline & $5.8 \pm 2.3^{\star \star \star}$ & $361.0 \pm 33.7^{\star \star \star}$ \\
\hline \multirow[t]{3}{*}{ Smart et al. (2014) } & $2.2 \pm 0.2^{\star}$ & $484 \pm 21^{*}$ \\
\hline & $2.3 \pm 0.2^{\star \star}$ & $479 \pm 16^{\star \star}$ \\
\hline & $3.0 \pm 0.2^{\star \star \star}$ & $464 \pm 16^{\star \star \star \star}$ \\
\hline \multirow[t]{2}{*}{ Tokuda et al. (2014)e,g } & $7.34 c^{\star \star \star}$ & $406 c^{\star \star \star}$ \\
\hline & $10.88 d^{\star \star \star}$ & $377 d^{\star \star \star}$ \\
\hline Tsolaki et al. (2015) ${ }^{g}$ & $3.5^{\star \star \star}$ & $428^{\star \star *}$ \\
\hline \multirow[t]{3}{*}{ Wang et al. (2013)e } & $18.5 \pm 9.2^{\star}$ & $351.9 \pm 32.2^{\star}$ \\
\hline & $15.2 \pm 4.4^{\star \star}$ & $348.8 \pm 33.9^{\star \star}$ \\
\hline & $17.9 \pm 3.3^{\star \star \star}$ & $355.9 \pm 31.3^{\star \star \star}$ \\
\hline Zhang, Ni and Chen (2014) ${ }^{\mathrm{e}, \mathrm{f}}$ & $5.2 \pm 1.9^{\star \star}$ & $340.4 \pm 23.7^{\star \star}$ \\
\hline Zhang et al. (2013) & $8.6 \pm 2.9^{\star \star}$ & $320.0 \pm 20.2^{\star \star}$ \\
\hline
\end{tabular}

aValues related to the ISI 800ms evaluation; ㅁalues related to the Go stimulus; ' Values related to healthy elderly with low arachidonic acid concentration; "Values related to healthy elderly with high arachidonic acid concentration; eValues related to baseline; 'Control group; 'studies did not report standard deviation from the mean. ${ }^{*} \mathrm{Fz}$ electrode; ${ }^{* *} \mathrm{Cz}$ electrode; ${ }^{\star * \star} \mathrm{Pz}$ electrode; ${ }^{\star \star \star \star} \mathrm{FCz}$ electrode.

pensatory mechanism to adequately perform the tasks. ${ }^{16}$ The reaction time to the stimuli differed between elderly and adults groups. For the elderly, it was a mean of 555 $\mathrm{ms}$, in middle-age adults $515 \mathrm{~ms}$ while the average among the young was $480 \mathrm{~ms} .{ }^{25}$ In one of the studies, poor performance on tasks involving working memory was associated with a higher latency value in elderly, and in relation to the amplitude, compared to the young, the elderly had higher values in frontal regions and smaller values in posterior regions. ${ }^{29}$ In the elderly, the activity is more distributed in the temporal and superior temporal lobes. ${ }^{5}$ Besides the changes related to age, differences were identified in the parietal and frontal regions. ${ }^{24,28}$

One of the articles analyzed showed that the changes in P300 are more pronounced in men, where latency increased by $2.3 \mathrm{~ms} /$ year in men and $1.6 \mathrm{~ms} /$ year in women. ${ }^{21}$ However, on topographic imaging exams, elderly men had greater distribution in the frontal region compared to women, responding to the stimulus faster. ${ }^{7}$

Education and cognitive tests showed no relationship with the results of the electrophysiological evaluations. However, the young had better performance 
on the $\mathrm{MMSE}^{17}$ and had over 10 years more education than the elderly, ${ }^{27}$ a factor which may have influenced age-related P300 results. These findings corroborate the results of the study by Miranda et al. (2012) ${ }^{2}$ in which no correlation was found between increase in P300 latency and education in elderly with hearing loss. A study carried out in Colombia of healthy elderly revealed an inverse relationship between latency and amplitude values; and, regarding gender and education, no differences were observed for the latency and amplitude of the P300 wave. ${ }^{37}$ One study found that bilingual elderly performed better than monolingual elderly on the electrophysiological measures during cognitive tasks. ${ }^{18}$

\section{P300: comparison between healthy elderly and those with mental disorders}

Regarding the use of P300 in mental disorders, most of the studies had used event-related potentials to evaluate whether differences existed between cognitively healthy elderly and subjects with cognitive loss and/or Alzheimer's disease (AD).

Three studies found that patients with $\mathrm{AD}$ had lower amplitude of the P300 wave when compared to healthy elderly. ${ }^{6,14,30}$ Although latency did not differ between the two groups in the study by Lee et al., ${ }^{14}$ it was higher for elderly with $\mathrm{AD}$ compared to healthy elderly with high and low risk of dementia in the study of Asaumi et al. (2014). ${ }^{6}$ In addition to these investigations, another study observed better latency and amplitude values for the group without subjective memory complaints than the group with complaints. ${ }^{31}$ In contrast, another investigation, ${ }^{2}$ despite identifying greater latency with increasing age, found no correlation of the P300 results with cognitive evaluation tests and depressive symptoms in elderly with hearing loss.

The relationship of $\mathrm{P} 300$ with cognitive loss and $\mathrm{AD}$ has been previously described in other studies. Since the P300 response is related to fundamental elements of cognitive function, it may be useful in the early diagnosis of dementia, serving as a complementary tool to existing instruments. ${ }^{11}$

A literature review evaluated whether the P300 was able to estimate the risk of progression from mild cognitive impairment (MCI) to AD. Eight studies were evaluated and found that the electrode positioned in the parietal region is the most effective to evaluate this progression, evidencing increased latency and decreased amplitude. However, despite being a promising method for evaluating this progression, such investigations remain scarce, with small samples and heterogeneous results. This demonstrates a need for further studies so that this tool can be used in clinical practice. ${ }^{38}$ Another meta-analysis of 13 papers investigated whether the P300 can serve as a useful neurophysiological marker to discriminate $\mathrm{MCI}$ and predict its progression. Differences were identified in P300 latency of patients with $\mathrm{MCI}$ when compared to controls and to patients with $\mathrm{AD}$, indicating that the this may be useful for identifying early cognitive impairment and its progression, including for $\mathrm{AD} .{ }^{4} \mathrm{~A}$ meta-analysis of twenty studies sought to characterize the $\mathrm{P} 300$ in probable $\mathrm{AD}$ compared with healthy controls and found that the amplitude was lower in individuals with $\mathrm{AD}^{39}$ Another systematic review of eight investigations found a consensus that the P300 latency is increased in elderly with $\mathrm{AD}$, but no consensus on amplitude (which may also be due to the methodological variations of the studies assessed). ${ }^{36}$

One of the evaluated articles in this review analyzed the association of P300 latency with the clinical stage of Parkinson's disease (PD). Latency values of the elderly with PD that exceeded two units from the standard deviation of the latency values of the healthy subjects were considered altered. In the group at initial stages of PD, $10 \%$ were considered altered and $31 \%$ at the advanced stages, showing an association between PD severity and increased P300 latency. ${ }^{13}$ The fact that the P300 serves as a possible predictor of $\mathrm{PD}$ evolution based on higher latency has been described previously. ${ }^{40}$

Another mental disorder found in the present review was depression. Zhang et al. (2013) ${ }^{22}$ evaluated stroke patients with and without depression versus a control group. The P300 latency values were higher, and amplitude values lower, in post-stroke patients with depression compared to the no depression and healthy groups. These data corroborate a study conducted in Australia that found greater amplitude and lower latency in patients with depression compared to those without depression, ${ }^{41}$ and also another in India, that found a delay in latency among patients with depression compared to healthy controls, which was proportional to disease severity. ${ }^{42}$

\section{P300 in clinical trials with healthy elderly}

Four trials with a total of 232 participants ${ }^{32-35}$ used the P300 measurement to identify the effects of the use of Bacopa monnieri ${ }^{32}$ and arachidonic acid, ${ }^{33}$ Tai Chi practice $^{34}$ and several sports modalities ${ }^{35}$ on cognitive processing in healthy elderly compared to controls. In all studies, the evaluation of P300 was sensitive for detecting the effects of therapies. Protocols ranged from 12 weeks to 18 months. These trials yielded important information, such as: when the treatment was inter- 
rupted, the P300 values returned to similar values to those before treatment began. ${ }^{32}$ During the therapy period, the control group of elderly continued to show increased latency and decreased amplitude compared to the elderly undergoing intervention, ${ }^{35}$ the electrophysiological evaluation may be improved with the use of other waves, such as Mismatch Negativity (MMN). ${ }^{34}$

One of the trials indicated that $\mathrm{Pz}$ would be a more sensitive electrode for detecting the effects of cognitive processing interventions. ${ }^{34}$ One of the articles reported information only for the electrode $\mathrm{Pz}^{33}$ while another only for the electrode $\mathrm{Cz} \cdot{ }^{35}$ Perhaps the sensitivity of the electrodes for detecting the effects depends on the characteristics of the sample of participants and type of intervention used. Therefore, it is up to the authors to decide what information from which electrode should be analyzed. Future studies could focus on the sensitivity of each electrode.

In the literature, other studies involving participants with different characteristics used the P300 to detect effects on cognitive processing of drug therapies, such as levetiracetam in the treatment of epilepsy ${ }^{43}$ use of perospirone in people with schizophrenia ${ }^{44}$ and donepezil in the elderly with vascular dementia type..$^{45}$ The P300 has also proved sensitive in clinical trials involving additional and complementary therapies, such as vitamin B12 supplementation ${ }^{46}$ and acupuncture. ${ }^{47}$

In clinical trials for the diagnosis of disorders, the P300 appears to be useful for identifying cognitive loss, age-related or otherwise, cognitive changes after complex surgical procedures and diagnoses for Alzheimer's disease. ${ }^{36}$ In other types of controlled clinical trials, the P300 was effective in identifying the influence of unhealthy habits, such as smoking. ${ }^{48}$ In summary, the electrophysiological evaluation by P300 seems to be a useful and sensitive tool to detect effects on cognitive processing in therapies with clinical trials and in studies of accuracy for diagnosing disorders.

\section{Main findings of the study}

This review aimed to systematize the latest information related to the use of P300 as a tool for cognitive processing assessment in healthy elderly. We found that:

- Most of the cross-sectional studies sought to identify the influence of age on endogenous ERP and showed an increase in latency and a decrease in amplitude with increasing age, due to the natural aging process. In elderly with cognitive loss, Alzheimer's disease, Parkinson's disease and depression, the increase in latency is more pronounced, including progressive decline according to the degree of cognitive impairment. There was no consensus on the reduction in amplitude in these cases.

- No relationship between the P300 and education was observed. Moreover, bilingual elderly performed better than monolingual elderly. However, there were no subjects with low education in the articles analyzed.

- The association between gender and P300 values is not well described in the literature. Some results indicate that men have greater latency with advancing years and faster response to frontal stimulus compared to women.

- This review was unable to indicate the normative values of amplitude and latency in healthy elderly. Among the eight studies that reported this information, the values ranged from $2.2 \mu \mathrm{V}$ to $18.5 \mu \mathrm{V}$ for amplitude, and from $320 \mathrm{~ms}$ to $484 \mathrm{~ms}$ for latency.

- Regarding visual and auditory evaluation, there are marked differences in the number of channels, electrode locations, impedance values, the number of rare and frequent stimuli used, stimulation differences regarding images (color, distance, type, size) or sounds (frequency, duration), among others.

- The focus of this review was healthy elderly. It was observed in all the articles that this group was used as a control for another group: young; elderly with mild cognitive impairment, Alzheimer's disease, Parkinson's disease, depression; or elderly receiving some intervention. Therefore, there is a lack of studies that specifically evaluated healthy elderly as the main focus.

Based on these results, further investigations should be conducted in order to:

- Evaluate the relationship between education and the P300 in elderly with different levels of literacy.

- Clarify the relationship of gender and education with variations in evoked potentials.

- Standardize the parameters used to evaluate and capture endogenous evoked potentials, allowing greater comparison between studies.

- Include healthy elderly as the main investigation group (and not only as a control group), following the evolution of this group over the years through longitudinal studies.

In conclusion, the reviewed scientific evidence suggests that there is an increase in latency and a decrease in amplitude with advancing age. Latency impairment is more pronounced in individuals with mental disorders, but no consensus exists with respect to amplitude. Normative values of amplitude and latency in healthy elderly cannot be established due to the variability in methodological characteristics, such as number of channels, electrode locations, impedance values, and differ- 
ences in stimulation procedures. Thus, there is no evidence on the association between gender, education and the P300 in healthy elderly. In clinical trials, the P300 has proven a useful tool to evaluate the effects of interventions in the elderly, but most studies used healthy elderly only as a control group.

Based on these results, it is suggested that further investigations should be conducted to evaluate the true relationship between age, education, gender and the P300 in elderly. Finally, as this review identified a lack of studies designed to specifically investigate cognitive processing in healthy aging using the $\mathrm{P} 300$, it is recommended that future studies include healthy elderly as the main investigation group.
Author contribution. All authors drafted and critically revised the manuscript.

\section{Acknowledgments.}

We extend our thanks to the Conselho Nacional de Desenvolvimento Científico e Tecnológico (CNPq) [Grant number 304068/2015-6] and Fundação de Amparo à Pesquisa do Estado de São Paulo (Grant number 2017/04129-9) for funding the Project. The funders had no role in the study design, data collection and analysis, decision to publish, or preparation of the manuscript.

\section{REFERENCES}

1. Salthouse TA. Selective review of cognitive aging. J Int Neuropsychol Soc. 2010;16:754-60.

2. Miranda EC, Pinheiro MMC, Pereira LD, lorio MCM. Correlation of the P300 evoked potential in depressive and cognitive aspects of aging. Braz J Otorhinolaryngol. 2012;78(5):83-9.

3. Rossini PM, Rossi S, Babiloni C, Polich J. Clinical neurophysiology of aging brain: From normal aging to neurodegeneration. Prog Neurobiol. 2007;83:375-400.

4. Jiang S, Qu C, Wang F, Liu Y, Qiao Z, Qu X, et al. Using event-related potential P300 as an electrophysiological marker for differential diagnosis and to predict the progression of mild cognitive impairment: a metaanalysis. Neurol Sci. 2015;36(7):1105-12.

5. Tsolaki A, Kosmidou V, Hadjileontiadis L, Kompatsiaris I, Tsolaki M. Brain source localization of MMN, P300 and N400: Aging and gender differences. Brain Res. 2015;1603:32-49.

6. Asaumi Y, Morita K, Nakashima Y, Muraoka A, Uchimura N. Evaluation of P300 components for emotion-loaded visual event-related potential in elderly subjects, including those with dementia. Psychiatry Clin Neurosci. 2014;68:558-67.

7. Brickman AM, Meier IB, Korgaonkar MS, Provenzano FA, Grieve SM, Siedlecki KL, et al. Testing the white matter retrogenesis hypothesis of cognitive aging. Neurobiol Aging. 2012;33(8):1699-715.

8. Cóser M, Cóser P, Pedroso FS, Rigon R, Cioqueta E. P300 auditory evoked potential latency in elderly. Braz $\mathrm{J}$ Otorhinolaryngol. 2010;76(3):287-93.

9. Dinteren R, Arns M, Jongsma MLA, Kessels RPC. P300 development across the lifespan: A systematic review and meta-analysis. PLoS One. 2014;9(2):1-13.

10. Parente MA de MP, Fonseca RP, Scherer LC. Literacy as a determining factor for brain organization: From Lecours' contribution to the present day. Dement Neuropsychol. 2008;2(3):165-72.

11. Vecchio F, Määttä S. The use of auditory event-related potentials in Alzheimer's disease diagnosis. Int J Alzheimers Dis. 2011;1-8.

12. Whittemore $R$, Knafl $K$. The integrative review: Updated methodology. Vol. 52, Journal of Advanced Nursing. 2005. p. 546-53.

13. Lopes M da S, Melo ADS, Nóbrega AC. Delayed latencies of auditory evoked potential P300 are associated with the severity of Parkinson's disease in older patients. Arq Neuropsiquiatr. 2014;72(4):296-300.

14. Lee M-S, Lee S-H, Moon E-O, Moon Y-J, Kim S, Kim S-H, et al. Neuropsychological correlates of the P300 in patients with Alzheimer's disease. Prog Neuropsychopharmacol Biol Psychiatry. 2013;40:62-9.

15. Alperin BR, Haring AE, Zhuravleva TY, Holcomb PJ, Rentz M, Daffner KR. The dissociation between early and late selection in older adults. $J$ Cogn Neurosci. 2013;25(12):2189-206.

16. Alperin BR, Mott KK, Rentz DM, Holcomb PJ, Daffner KR. Investigating the age-related "anterior shift" in the scalp distribution of the P3b component using principal component analysis. Psychophysiology. 2014;51:620-33
17. Alperin BR, Mott KK, Holcomb PJ, Daffner KR. Does the age-related "anterior shift" of the P3 reflect an inability to habituate the novelty response? Neurosci Lett. 2014;577:6-10.

18. Kousaie S, Phillips NA. A behavioural and electrophysiological investigation of the effect of bilingualism on aging and cognitive control. Neuropsychologia. 2017;94:23-35.

19. O'Connell RG, Balsters JH, Kilcullen SM, Campbell W, Bokde AW, Lai $\mathrm{R}$, et al. A simultaneous ERP/fMRI investigation of the P300 aging effect. Neurobiol Aging. 2012;33(10):2448-61.

20. Speer ME, Soldan A. Cognitive reserve modulates ERPs associated with verbal working memory in healthy younger and older adults. Neurobiol Aging. 2015;36(3):1424-34.

21. Kuba M, Kremlacek J, Langrova J, Kubova Z, Szanyi J, Vit F. Aging effect in pattern, motion and cognitive visual evoked potentials. Vision Res. 2012;62:9-16.

22. Zhang Z, Mu J, Li J, Li W, Song J. Aberrant apolipoprotein E expression and cognitive dysfunction in patients with poststroke depression. Genet Test Mol Biomarkers. 2013;17(1):47-51.

23. Bashore TR, Wylie SA, Ridderinkhof KR, Martinerie JM. Responsespecific slowing in older age revealed through differential stimulus and response effects on P300 latency and reaction time. Neuropsychol Dev Cogn B Aging Neuropsychol Cogn. 2014;21(6):633-73.

24. Li L, Fabiani M, Knight RT. Age-related frontoparietal changes during the control of bottom- up and top-down attention: an ERP study. Neurobiol Aging. 2013;34(2):477-88.

25. Lucci G, Berchicci M, Spinelli D, Taddei F, Di Russo F. The Effects of Aging on Conflict Detection. PLoS One. 2013;8(2):1-14.

26. Nowak K, Oron A, Szymaszek A, Leminen $M$, Näätänen R, Szelag E. Electrophysiological indicators of the age-related deterioration in the sensitivity to auditory duration deviance. Front Aging Neurosci. 2016;8:1-10.

27. Raggi A, Tasca D, Rundo F, Ferri R. Stability of auditory discrimination and novelty processing in physiological aging. Behav Neurol. 2013;27:193-200

28. Richardson C, Bucks RS, Hogan AM. Effects of aging on habituation to novelty: An ERP study. Int J Psychophysiol. 2011;79(2):97-105.

29. Saliasi E, Geerligs L, Lorist MM, Maurits NM. The Relationship between P3 Amplitude and Working Memory Performance Differs in Young and Older Adults. PLoS One. 2013;8(5):1-9.

30. Bender S, Bluschke A, Dippel G, Rupp A, Weisbrod M, Thomas C. Auditory post-processing in a passive listening task is deficient in Alzheimer's disease. Clin Neurophysiol. 2014;125:53-62.

31. Smart CM, Segalowitz SJ, Mulligan BP, MacDonald SWS. Attention capacity and self-report of subjective cognitive decline: A P3 ERP study. Biol Psychol. 2014;103:144-51.

32. Peth-Nui T, Wattanathorn J, Muchimapura S, Tong-Un T, Piyavhatkul N, Rangseekajee P, et al. Effects of 12-week bacopa monnieri consumption on attention, cognitive processing, working memory, and functions of 
both cholinergic and monoaminergic systems in healthy elderly volunteers. Evidence-based Complement Altern Med. 2012;2012:10 pages.

33. Tokuda H, Kontani M, Kawashima H, Akimoto K, Kusumoto A, Kiso Y, et al. Arachidonic acid-enriched triacylglycerol improves cognitive function in elderly with low serum levels of arachidonic acid. J Oleo Sci. 2014;63(3):219-27.

34. Wang W, Qiu C, Ota T, Swada M, Kishimoto N, Kishimoto T. Effects of Tai Chi Exercise on the healthy elderlt as measured by event-related potentials. J Nara Med Assoc. 2013;64(5):87-94.

35. Zhang X, Ni X, Chen P. Study about the effects of different fitness sports on cognitive function and emotion of the aged. Cell Biochem Biophys. 2014;70:1591-6.

36. Pedroso RV, Fraga FJ, Corazza DI, Andreatto CAA, Coelho FG de M, Costa JLR, et al. Latência e amplitude do P300 auditivo na doença de Alzheimer: uma revisão sistemática. Braz J Otorhinolaryngol. 2012; 78(4):126-32.

37. Gutiérrez Giraldo N, Rangel Galvis CE, Tovar C. JR. Cognitive Evoked Potential Measurement, P300, in a group of healthy Colombian individuals. Rev Ciencias la Salud. 11(2):195-204.

38. Cintra MTG, Silva Tavares MC, Gomes SA, Gonçalves TO, Cunha LCM, Gonçalves DUG, et al. P300 Evoked Potential and Risk of Mild Cognitive Impairment Progression to Alzheimers Dementia: A Literature Review. Gomes SA, editor. Vol. 6, Journal of Neurology \& Neurophysiology. OMICS International.,; 2015. p. 1-5.

39. Hedges D, Janis R, Mickelson S, Keith C, Bennett D, Brown BL. P300 Amplitude in Alzheimer's Disease: A Meta-Analysis and Meta-Regression. Clin EEG Neurosci. 2016;47(1):48-55.

40. Chen KJ, Lin RT, Liu CK, Tai CT, Lai CL. Relationship between event- related potentials and frontal-subcortical dysfunction in Parkinson's disease. Park Relat Disord. 2006;12(7):453-8.

41. Patterson JL, Barber JB, O'Connor DW, Toukhsati R. Electrophysiological Profiling of Depression in the Elderly. Arch Depress Anxiety. 2016;2(1):31-6.

42. Tripathi SM, Mishra N, Tripathi RK, Gurnani KC. P300 latency as an indicator of severity in major depressive disorder. Vol. 24, Industrial Psychiatry Journal. India; 2015. p. 163-7.

43. Tumay Y, Altun Y, Ekmekci K, Ozkul Y. The effects of levetiracetam, carbamazepine, and sodium valproate on P100 and P300 in epileptic patients. Clin Neuropharmacol. 2013;36(2):55-8.

44. Sumiyoshi T, Higuchi Y, Itoh T, Matsui M, Arai H, Suzuki M, et al. Effect of perospirone on P300 electrophysiological activity and social cognition in schizophrenia: a three-dimensional analysis with sloreta. Psychiatry Res. 2009;172(3):180-3.

45. Paci C, Gobbato R, Carboni T, Sanguigni S, Santone A, Curatola L. P300 auditory event-related potentials and neuropsychological study during donepezil treatment in vascular dementia. Neurol Sci Off J Ital Neurol Soc Ital Soc Clin Neurophysiol. 2006;26(6):435-7.

46. Kalita J, Agarwal R, Chandra S, Misra UK. A study of neurobehavioral, clinical psychometric, and P3 changes in vitamin B12 deficiency neurological syndrome. Nutr Neurosci. 2013;16(1):39-46.

47. Liu F, Li Z-M, Jiang Y-J, Chen L-D. A meta-analysis of acupuncture use in the treatment of cognitive impairment after stroke. J Altern Complement Med. 2014;20(7):535-44.

48. Evans DE, Jentink KG, Sutton SK, Van Rensburg KJ, Drobes DJ. 7 mg nicotine patch fails to enhance P300 neural indices of cognitive control among nonsmokers. Pharmacol Biochem Behav. 2014;126:77-82. 